
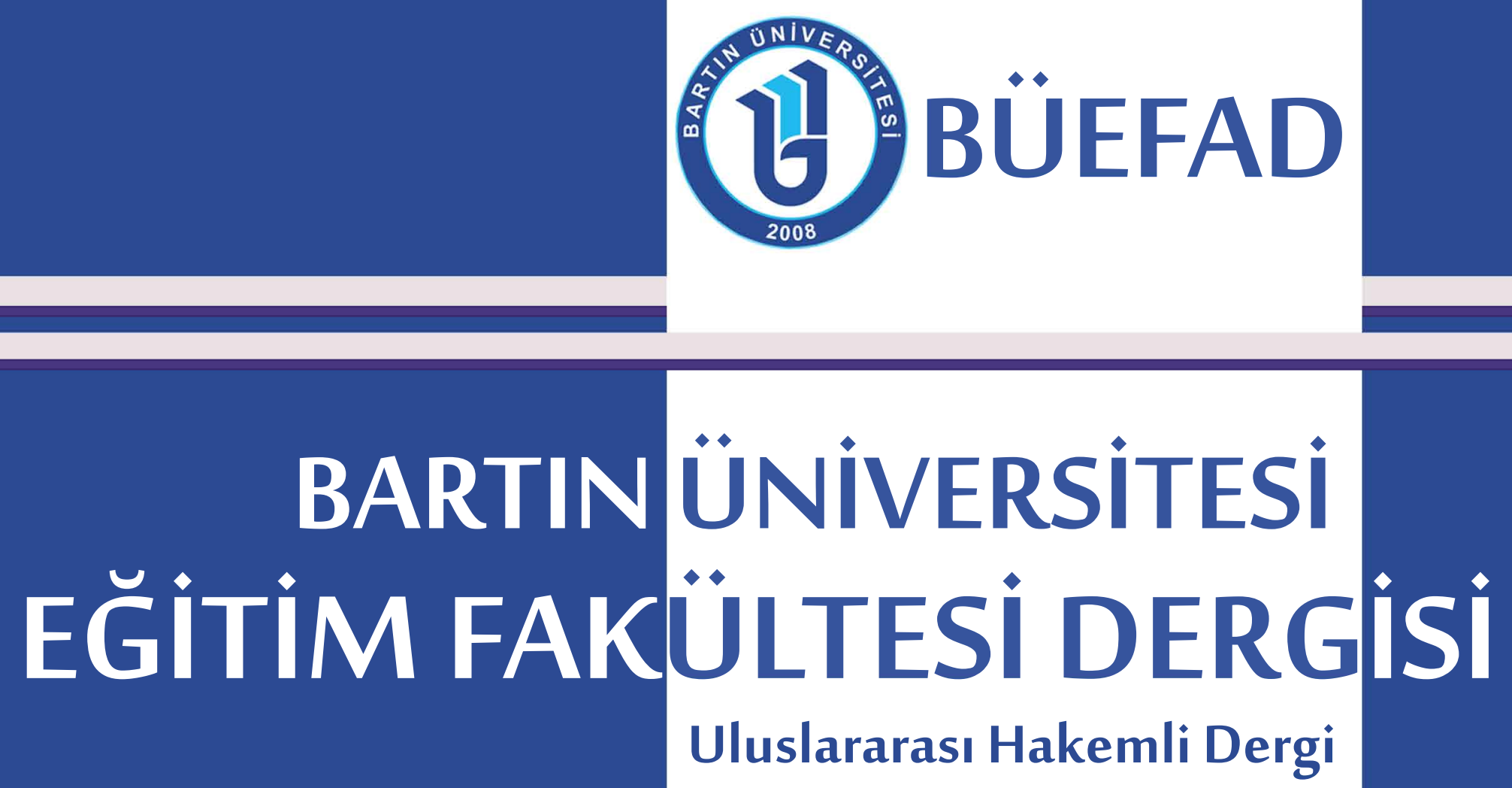

\section{- AYRI BASIM -}

Yrd. Doç. Dr. Serkan TíMUR Şirin YILMAZ

Yrd. Doç. Dr. Betül TíMUR

Fen ve Teknoloji Öğretmenleri İle öğretmen Adaylarının Fen Deneylerinin Amaçlarını Kavramaya Yönelik Tutumlarının İncelenmesi

BARTINUNIVERSITY JOURNAL

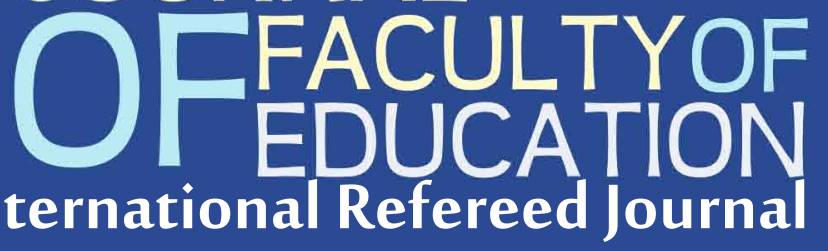

Cilt/Volume: $3 \quad$ Sayı/Issue: 1 Yaz/Summer 2014 ISSN 1308-7177

\section{- SPECIAL EDITION -}

Asst. Prof. Serkan TIMUR

Sirin YILMAZ

Asst. Prof. Betul TIMUR

Investigating Science and Technology Teachers' and

Pre-Service Teachers' Attitudes towards Understanding the Objectives of Science Experiments

ProcessForm

Objectives

Pre-Service

Models $\prod_{\text {vechma }}$ venology

Profession
Verbal Supervision Validity

Study Investigating Turkish

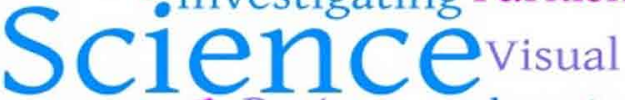

Iอ

Candidatest $1-1$ Scale

Education LOWaras

Digital

Digital Supervisors

Teacher Mathematics Profiles

Examination Processing

Assisted Reliability Algısı

ÖzyeterlilikEleștirel

Attitudes ${ }^{\text {Style }}$

2014-3

Teaching Features University

Güvenirlik Geçerlilik

Çalışması Analysis

Example Speech 


\section{BARTIN ÜNIVERSİTesi EĞítim FAKüLTESI DERgisi}

BARTIN UNIVERSITY JOURNAL OF FACULTY OF EDUCATION

Cilt/ Volume: 3, Say1/Issue: 1, Yaz / Summer 2014

ISSN:1308-7177

\section{$\underline{\text { Sahibi }}$}

Bartın Üniversitesi Eğitim Fakültesi Adına Prof. Dr. Firdevs GÜNEŞ (Dekan)

Editör

Yrd. Doç. Dr. Sedat BALYEMEZ

\section{Alan Editörleri}

Doç. Dr. Çetin SEMERCi

Doç. Dr. Necati HIRÇA

Doç. Dr. Nuriye SEMERCi

Yrd. Doç. Dr. Ayşe Derya IŞIK

Yrd. Doç. Dr. Meliha KÖSE

Yrd. Doç. Dr. Neslihan USTA

Yrd. Doç. Dr. Sevan NART

Yrd. Doç. Dr. Sinem TARHAN

Yrd. Doç. Dr. Süreyya GENÇ

Yabancı Dil Sorumlusu

Yrd. Doç. Dr. Özge GÜN

\section{Yayıma Hazırlık}

Arş. Gör. Arzu ÇEVIK

Arş. Gör. Ömer KEMiksiz

\section{Sekretarya}

Arş. Gör. Hasan Basri KANSIZOĞLU

\section{Teknik Sorumlular}

Arş. Gör. Barış ÇUKURBAŞı

Arş. Gör. Fatma Gizem KARAOĞLAN YILMAZ

\section{İetişim}

Bartın Üniversitesi Eğitim Fakültesi

74100 BARTIN - TÜRKIYE

e-posta: buefad@bartin.edu.tr

Tel: +903782235219

Bartın Üniversitesi Eğitim Fakültesi Dergisi (BÜEFAD), yılda iki kez yayımlanan uluslararası hakemli bir dergidir. Yazıların sorumluluğu, yazarlarına aittir.
Owner

On Behalf of Bartin University Faculty of Education Prof. Firdevs GUNES (Dean)

$\underline{\text { Editor }}$

Asst. Prof. Sedat BALYEMEZ

Field Editors

Assoc. Prof. Cetin SEMERCI

Assoc. Prof. Necati HIRCA

Assoc. Prof. Nuriye SEMERCI

Asst. Prof. Ayse Derya ISIK

Asst. Prof. Meliha KOSE

Asst. Prof. Neslihan USTA

Asst. Prof. Sevan NART

Asst. Prof. Sinem TARHAN

Asst. Prof. Sureyya GENC

Foreign Language Specialist

Asst. Prof. Ozge GUN

Preparing for Publication

RA. Arzu CEVIK

RA. Omer KEMIKSIZ

Secretary

RA. Hasan Basri KANSIZOGLU

$\underline{\text { Technical Assistants }}$

RA. Baris CUKURBASI

RA. Fatma Gizem KARAOGLAN YILMAZ

Contact

Bartin University Faculty of Education 74100 BARTIN - TURKEY

e-mail: buefad@bartin.edu.tr

Tel: +90 3782235219

Bartin University Journal of Faculty of Education (BUJFED) is a international refereed journal that is published two times a year. The responsibility lies with the authors of papers. 


\section{DiZINLENME VE LISTELENME / INDEXING AND LISTING}

Bartın Üniversitesi Eğitim Fakültesi Dergisi, aşağıdaki indeksler tarafından dizinlenmekte ve listelenmektedir. / Bartin University Journal of Faculty of Education is indexed and listed by the following indexes.

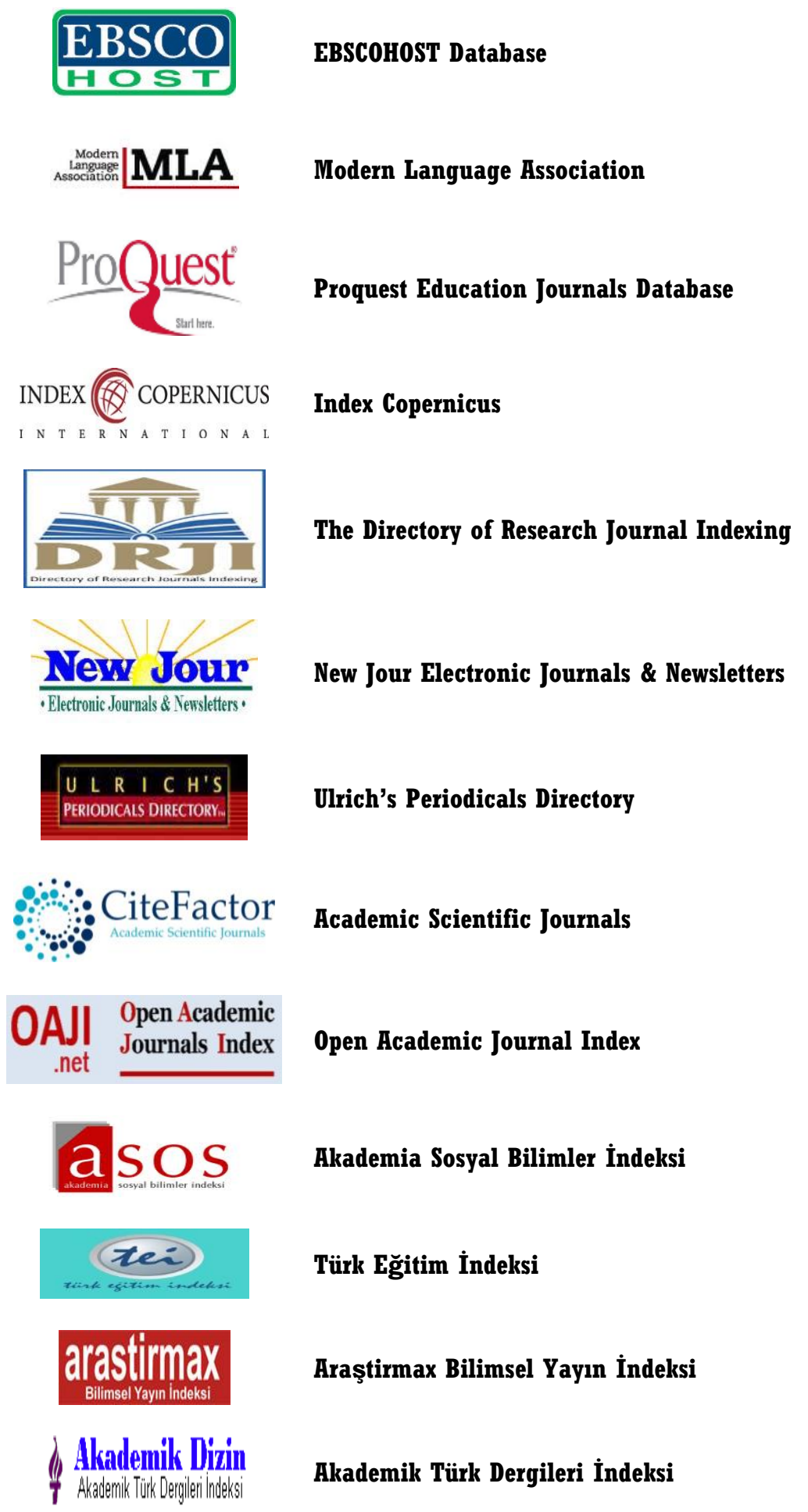


YAYIN DANIŞMA KURULU / EDITORIAL ADVISORYBOARD

Prof. Dr. Ahmet ARIKAN

Prof. Dr. Ahmet GÜNŞEN

Prof. Dr. Ahmet SABAN

Prof. Dr. Aziz KILINÇ

Prof. Dr. Bilgin Ünal iBRET

Prof. Dr. Cemal TOSUN

Prof. Dr. Firdevs GÜNEŞ

Prof. Dr. Firdevs KARAHAN

Prof. Dr. Ahmet KIRKILIÇ

Prof. Dr. Hayati AKYOL

Prof. Dr. Hüseyin ALKAN

Prof. Dr. M. Fatih TAŞAR

Prof. Dr. Mimar TÜRKKAHRAMAN

Prof. Dr. Murat ÖZBAY

Prof. Dr. Ramazan KAPLAN

Prof. Dr. Recai DOĞAN

Prof. Dr. Safure BULUT

Prof. Dr. Sebahattin ARIBAŞ

Prof. Dr. Selahattin TURAN

Prof. Dr. Selma YEL

Prof. Dr. Şefik YAŞAR

Prof. Dr. Yavuz TAŞKESENLIGIL

Doç. Dr. Bahri ATA

Doç. Dr. Çavuş ŞAHIN

Doç. Dr. Çetin SEMERCi

Doç. Dr. Emine KOLAÇ

Doç. Dr. Erol DURAN

Doç. Dr. Eyyüp COŞKUN

Doç. Dr. Kubilay YAZICI

Doç. Dr. Neşe TERTEMiz

Doç. Dr. Nuriye SEMERCi

Doç. Dr. Sabri SIDEKLi

Doç. Dr. Tolga GÜYER
Gazi Üniversitesi

Trakya Üniversitesi

N. Erbakan Üniversitesi

ÇOMÜ

Kastamonu Üniversitesi

Ankara Üniversitesi

Bartın Üniversitesi

Sakarya Üniversitesi

Atatürk Üniversitesi

Gazi Üniversitesi

Dokuz Eylül Üniversitesi

Gazi Üniversitesi

Akdeniz Üniversitesi

Gazi Üniversitesi

Bartın Üniversitesi

Ankara Üniversitesi

ODTÜ

Adıyaman Üniversitesi

Osmangazi Üniversitesi

Gazi Üniversitesi

Anadolu Üniversitesi

Atatürk Üniversitesi

Gazi Üniversitesi

ÇOMÜ

Bartın Üniversitesi

Anadolu Üniversitesi

Uşak Üniversitesi

Mustafa Kemal Üniversitesi

Niğde Üniversitesi

Gazi Üniversitesi

Bartın Üniversitesi

Muğla S. Koçman Üniversitesi

Gazi Üniversitesi 


\section{BU SAYININ HAKEMLERI / REFEREES OFTHIS ISSUE}

Prof. Dr. Ahmet KAÇAR

Prof. Dr. Adnan BAKi

Prof. Dr. Fatma AÇIK

Prof. Dr. Firdevs GÜNEŞ

Prof. Dr. Firdevs KARAHAN

Prof. Dr. Hasan BACANLI

Prof. Dr. Yusuf BUDAK

Doç. Dr. Ali TAŞ

Doç. Dr. Çetin SEMERCi

Doç. Dr. Ebru KILIÇ ÇAKMAK

Doç. Dr. Eyyüp COŞKUN

Doç. Dr. Halit KARATAY

Doç. Dr. Gökhan DEMIRCioĞLU

Doç. Dr. Levent ERASLAN

Doç. Dr. Mehmet Ali ÇAKMAK

Doç. Dr. Mehmet Altan KURNAZ

Doç. Dr. Mustafa ULUSOY

Doç. Dr. Mübin KIYICI

Doç. Dr. Necati HIRÇA

Doç. Dr. Nuriye SEMERCi

Doç. Dr. Orhan AKINOĞLU

Doç. Dr. Özay KARADAĞ

Doç. Dr. Özlem ÇAKMAK

Doç. Dr. Sabri SIDEKLI

Doç. Dr. Yüksel GÖĞEBAKAN

Yrd. Doç. Dr. Abdullah Çağrı BiBBER

Yrd. Doç. Dr. Ahmet YIKMIŞ

Yrd. Doç. Dr. Ahmet AKKAYA

Yrd. Doç. Dr. Ali Rıza ŞEKERCi

Yrd. Doç. Dr. Aslıhan SABAN

Yrd. Doç. Dr. Aynur KOLBURAN GEÇER

Yrd. Doç. Dr. Ayşe Derya IŞIK

Yrd. Doç. Dr. Ayşe GÜLER

Yrd. Doç. Dr. Burcu DUMAN

Yrd. Doç. Dr. Cemal TOSUN

Yrd. Doç. Dr. Çığıl AYKUT

Yrd. Doç. Dr. Devrim AKGÜNDÜZ

Yrd. Doç. Dr. Fulya TOPÇUOĞLU ÜNAL

Yrd. Doç. Dr. Gamze Elif TANINMIŞ

Yrd. Doç. Dr. Güliz AYDIN

Yrd. Doç. Dr. İbrahim GÖKTAŞ

Yrd. Doç. Dr. İlhan YALÇIN
Kastamonu Üniversitesi

Karadeniz Teknik Üniversitesi

Gazi Üniversitesi

Bartın Üniversitesi

Sakarya Üniversitesi

Yıldız Teknik Üniversitesi

Gazi Üniversitesi

Kırıkkale Üniversitesi

Bartın Üniversitesi

Gazi Üniversitesi

Mustafa Kemal Üniversitesi

Abant İzzet Baysal Üniversitesi

Ondokuz Mayıs Üniversitesi

Kırıkkale Üniversitesi

Gazi Üniversitesi

Kastamonu Üniversitesi

Gazi Üniversitesi

Sakarya Üniversitesi

Bartın Üniversitesi

Bartın Üniversitesi

Marmara Üniversitesi

Düzce Üniversitesi

Gazi Üniversitesi

Muğla Sıtkı Koçman Üniversitesi

İnönü Üniversitesi

Kastamonu Üniversitesi

Abant İzzet Baysal Üniversitesi

Adıyaman Üniversitesi

Dumlupınar Üniversitesi

Konya Üniversitesi

Kocaeli Üniversitesi

Bartın Üniversitesi

Kırıkkale Üniversitesi

Bartın Üniversitesi

Bartın Üniversitesi

Gazi Üniversitesi

İstanbul Aydın Üniversitesi

Dumlupınar Üniversitesi

Gazi Üniversitesi

Ordu Üniversitesi

Adnan Menderes Üniversitesi

Ankara Üniversitesi 
Yrd. Doç. Dr. M. Sani ADIGÜZEL

Yrd. Doç. Dr. Mehmet Diyaddin YAŞAR

Yrd. Doç. Dr. Mehmet UMUZDAŞ

Yrd. Doç. Dr. Metin DENIZ

Yrd. Doç. Dr. Murat GENÇ

Yrd. Doç. Dr. Nail iLHAN

Yrd. Doç. Dr. Nalan OKAN AKIN

Yrd. Doç. Dr. Nuray MAMUR

Yrd. Doç. Dr. Özcan KARAASLAN

Yrd. Doç. Dr. Özge GÜN

Yrd. Doç. Dr. Sedat BALYEMEZ

Yrd. Doç. Dr. Semra KIRANLI GÜNGÖR

Yrd. Doç. Dr. Sibel SADI

Yrd. Doç. Dr. Suad SAKALLI GÜMÜŞ

Yrd. Doç. Dr. Sultan Bilge KARA

Yrd. Doç. Dr. Süleyman AVCI

Yrd. Doç. Dr. Şenel ELALDI

Yrd. Doç. Dr. Şeyda GÜL

Yrd. Doç. Dr. Tolga KABACA

Yrd. Doç. Dr. Tuncay Yavuz ÖZDEMiR

Yrd. Doç. Dr. Yakup DOĞAN

Dr. Hayriye Tuğba ÖZTÜRK
İstanbul Aydın Üniversitesi

Kilis 7 Aralık Üniversitesi

Gaziosmanpaşa Üniversitesi

Bartın Üniversitesi

Düzce Üniversitesi

Kilis 7 Aralık Üniversitesi

Niğde Üniversitesi

Pamukkale Üniversitesi

Marmara Üniversitesi

Bartın Üniversitesi

Bartın Üniversitesi

Eskişehir Osmangazi Üniversitesi

Kafkas Üniversitesi

Mustafa Kemal Üniversitesi

Okan Üniversitesi

Marmara Üniversitesi

Cumhuriyet Üniversitesi

Atatürk Üniversitesi

Pamukkale Üniversitesi

FIrat Üniversitesi

Kilis 7 Aralık Üniversitesi

Ankara Üniversitesi 


\section{IÇINDEKILER / CONTENTS}

\section{Prof. Dr. Firdevs GÜNEŞ}

Konuşma Öğretimi Yaklaşım ve Modelleri

Speech Teaching Approaches and Models

doi number: 10.14686/BUEFAD.201416205

\section{Barış ÇUKURBAŞı - Prof. Dr. Aytekin IŞMAN}

Öğretmen Adaylarının Dijital Yerli Özelliklerinin Incelenmesi (Bartın Üniversitesi Örneği)

Examination of Teacher Candidates' Digital Natives Features (Example of Bartın University)

doi number: 10.14686/BUEFAD.201416206

Yrd. Doç. Dr. Süleyman GÖKSOY - Doç. Dr. Engin ASLANARGUN

Denetim Sürecinde Eğitim Denetmenlerinin Davranışları

Behaviours of Supervisors in the Process of Supervision

$55-77$

doi number: 10.14686/BUEFAD.201416207

Arş. Gör. Yunus ÖZYURT - Doç. Dr. Altay EREN

Fen Bilgisi Öğretmen Adaylarının Öğretmenlik Mesleğine ve Kopya Çekmeye Yönelik Tutumlarının Görünümü

Profiles of Pre-Service Science Teachers' Attitudes towards the Teaching Profession and Cheating doi number: 10.14686/BUEFAD.201416208

\section{Yrd. Doç. Dr. Sefa DÜNDAR}

The Investigation of Spatial Skills of Prospective Teachers with Different Cognitive

Bilissel Stilleri Farklı Ogretmen Adaylarının Uzamsal Becerilerinin Incelenmesi

doi number: 10.14686/BUEFAD.201416209

Yrd. Doç. Dr. Abdulkerim KARADENiz

Eleştirel Okuma Özyeterlilik Algısı Ölçeğinin Geçerlilik ve Güvenirlik Çalışması

Critical Reading Self-Efficacy Perception Scale Validity and Reliability Study

doi number: 10.14686/BUEFAD.201416210

Yrd. Doç. Dr. Ayşen KARAMETE - Öğr. Gör. Hüseyin GÜNEŞ

İlköğretim Seçmeli Satranç Dersi Başlangıç Düzeyi Birinci Basamak Bilgisayar Destekli Öğretim Tasarımı

Primary School First Grade Beginner Level Chess Course Computer-Aided Instructional Design

doi number: 10.14686/BUEFAD.201416211

Doç. Dr. Fahri TEMizYÜREK - Arş. Gör. Arzu ÇEVIK

Mustafa Ruhi Şirin'in Çocuk Edebiyatı Sahasındaki Eserlerinin Dil ve Kavram Bağlamında İncelenmesi

Examination of Mustafa Ruhi Sirin's Works in Field of Children's Literature According to Context of Language

Concept

doi number: 10.14686/BUEFAD.201416212

Dr. Gizem KARAOĞLAN YILMAZ - Dr. Ramazan YILMAZ - Arş. Gör. Barış SEZER

Üniversite Öğrencilerinin Güvenli Bilgi ve İletişim Teknolojisi Kullanım Davranışları ve Bilgi Güvenliği Eğitimine Genel Bir Bakış

Secure Information and Communication Technology Usage Behavior of University Students and an Overview

to Information Security Training

$176-199$

doi number: 10.14686/BUEFAD.201416213 


\section{IÇINDEKILER / CONTENTS}

\section{Yrd. Doç. Dr. Erdal TAŞLIDERE}

Kavramsal Değişim Yaklaşımının Doğru Akım Devreleri Konusundaki Kavram Yanılgılarının Giderilmesine Etkisi

Effect of Conceptual Change Instruction on Remedying Misconceptions Concerning Direct Current Circuits doi number: 10.14686/BUEFAD.201416214

\section{Dr. H. Tuğba ÖzTÜRK}

Küreselleşme ve Ağ Toplumları Odağında Bilgi ve Illetişim Teknolojileri ile Eğitim Education with Information and Communication Technologies in the Scope of Globalisation and Network Society doi number: 10.14686/BUEFAD.201416215

Yrd. Doç. Dr. Serkan TiMUR - Şirin YILMAZ - Yrd. Doç. Dr. Betül TiMUR Fen ve Teknoloji Öğretmenleri İle Öğretmen Adaylarının Fen Deneylerinin Amaçlarını Kavramaya Yönelik Tutumlarının İncelenmesi Investigating Science and Technology Teachers' and Pre-Service Teachers' Attitudes towards Understanding the Objectives of Science Experiments doi number: 10.14686/BUEFAD.201416216

\section{Fazilet Eda YILMAZ - Gülşah TOPALOĞLU - Mustafa AKYÜZLÜER}

Grupla Yapılan Müzik Etkinliğinin Otizmli Çocukların Sosyal Becerilerine Etkisinin Betimlenmesi

Description of the Effect of Musical Activity with Group on Social Skills of Children with Autism doi number: 10.14686/BUEFAD.201416217

Yrd. Doç. Dr. Özcan Erkan AKGÜN - Şirin KÜçÜK

Barış ÇUKURBAŞI - İsmail TONBULOĞLU

Sözel veya Görsel Baskın Öğrenme Stilini Belirleme Ölçeği Türkçe Formunun Geçerlik ve Güvenirlik Çalışması

Validity and Reliability Study of the Visual versus Verbal Style of Processing Scale Turkish Form doi number: 10.14686/BUEFAD.201416218

Arş. Gör. Ruhşen ALDEMiR - Doç. Dr. Enver TATAR Teknoloji Destekli Matematik Eğitimi Hakkında Yayınlanan Makalelerinin İncelenmesi An Analysis of Articles on Technology Assisted Mathematics Education doi number: 10.14686/BUEFAD.201416219

İsmail TONBULOĞLU - Prof. Dr. Aytekin IŞMAN

Öğretmenlerin Sosyal Ağları Kullanım Profillerinin İncelenmesi

Exploring Teachers' Social Network Usage

doi number: 10.14686/BUEFAD.201416220

Arş. Gör. Dr. Osman çiMEN - Prof. Dr. Mehmet YILMAZ Dönüşümsel Öğrenme Kuramına Dayalı Çevre Eğitiminin Biyoloji Öğretmen Adaylarının Çevre Sorunlarına Yönelik Algılarına Etkisi The Influence of Transformative Learning Based Environmental Education on Preservice Biology Teachers' Perception of Environmental Problems doi number: 10.14686/BUEFAD.201416221

Doç. Dr. İ. Halil TÜRKER - Yrd. Doç. Dr. Fatih ÖZDEMiR Resim-İş Eğitimi Programları Grafik Ana Sanat Ders İçerikleri ve İşleniş Biçimleri Course Outlines and Teaching Styles at Graphic Design Lessons at Fine Arts Education Departments doi number: 10.14686/BUEFAD.201416222 


\section{IÇINDEKILER / CONTENTS}

\section{Yrd. Doç. Dr. Süreyya GENÇ}

Sanat Eğitiminde Eğitsel Oyunların Önemi

Importance of Educational Games in Arts Education

doi number: 10.14686/BUEFAD.201416223

Doç. Dr. Lale HÜSEYNOVA

Müzik Öğretmenliği Bölümü Öğrencilerinin Keman Çalma Performanslarını Etkileyen Bazı Değişkenler

Some Variables that Affect the Violin - Playing Performance of Students in the Department of Music Teaching doi number: 10.14686/BUEFAD.201416224

\section{Yrd. Doç. Dr. Vafa SAVAŞKAN}

Eğitim Fakültesi Öğrencilerinin Günlük Tutma Alışkanlıklarının Öğrenci Görüşleri Doğrultusunda İncelenmesi

Investigate the Logging Habits of the Faculty of Education Students in Terms of Students' Opinion doi number: 10.14686/BUEFAD.201416225

Arş. Gör. Melehat GEZER - Prof. Dr. İbrahim Fevzi ŞAHIN

Yrd. Doç. Dr. Meral ÖNER SÜNKÜR - Arş. Gör. Elif MERAL

8. Sınıf Türkiye Cumhuriyeti İnkılâp Tarihi ve Atatürkçülük Dersi Öğretim Programı Kazanımlarının Revize Edilmiş Bloom Taksonomisine Göre Değerlendirilmesi

An Evaluation of the Outcomes of the 8th Grade History of Turkish Revolution and Kemalism Lesson According to Revized Bloom's Taxonomy doi number: 10.14686/BUEFAD.201416226

Prof. Dr. Firdevs GÜNEŞ - Doç. Dr. Coşkun ARSLAN - Arş. Gör. Ayşe ELiÜşÜK Atılganlık Eğitiminin Üniversite Öğrencilerinin Kişiler Arası Problem Çözme, Algılanan Sosyal Destek ve Atılganlık Düzeyleri Üzerine Etkisi 


\title{
Fen ve Teknoloji Öğretmenleri İle Öğretmen Adaylarının Fen Deneylerinin Amaçlarını Kavramaya Yönelik Tutumlarının Incelenmesi
}

\author{
Yrd. Doç. Dr. Serkan TiMUR \\ Çanakkale Onsekiz Mart Üniv. \\ Eğitim Fakültesi \\ serkantimur42@gmail.com
}

\author{
Şirin YILMAZ \\ Abant İzzet Baysal Üniversitesi \\ Eğitim Fakültesi \\ sirinyilmaz87@gmail.com
}

\author{
Yrd. Doç. Dr. Betül TiMUR \\ Çanakkale Onsekiz Mart Üniv. \\ Eğitim Fakültesi \\ betultmr@gmail.com
}

Özet: Bu çalışmanın amacı fen ve teknoloji öğretmenleri ile öğretmen adaylarının fen deneylerinin amaçlarını kavramaya yönelik tutumlarını bazı değişkenlere göre incelemektir. Çalışma toplam 128 kişi ile yürütülmüştür. Çalışmada tarama modeli kullanılmıştır. Çalışmada veri toplama aracı olarak Yıldız, Akpınar, Aydoğdu ve Ergin (2006) tarafından geliştirilen 'Fen Deneylerinin Amaçlarııı Kavramaya Yönelik Tutum Ölçeği (FDAYTÖ)' kullanılmıştır. Yapılan analizler sonucunda fen ve teknoloji öğretmenleri ve öğretmen adaylarının fen deneylerinin amaçlarını kavramaya yönelik tutumları arasında istatistiksel olarak anlamlı bir fark bulunmamıştır. Cinsiyet değişkenine göre de tutum puanları arasında anlamlı bir fark yoktur. Buna karşın öğretmen ve öğretmen adaylarının, fen ve teknolojideki yenilikleri takip etme durumu ve fen ve teknoloji ile ilgili haber ve bilgileri merak düzeyi arttıkça fen deneylerinin amaçlarını kavramaya yönelik tutumları da artmaktadır.

Anahtar Kelimeler: Fen ve Teknoloji Dersi, Fen Deneyleri, Fen ve Teknoloji Öğretmeni, Öğretmen Adayı, Tutum.

\section{Investigating Science and Technology Teachers' and Pre-Service Teachers' Attitudes towards Understanding the Objectives of Science Experiments}

\begin{abstract}
The current research aims to investigate science and technology teachers' and science and technology pre-service teachers' attitudes towards understanding the objectives of science experiments, on some variables. The study carried out with a total of 128 people. Survey model was used in the study. The data collection tool of the study was 'Attitude Test of Understanding the Objectives of Science Experiments (ATUOSE)' developed by Yildiz, Akpinar, Aydogdu, and Ergin (2006). The reliability coefficient of the scale was found as Cronbach's Alpha .96. Analyses showed no statistically significant difference between the science and technology teachers' and pre-service teachers' attitudes towards understanding the objectives of science experiments. There was not a statistically significant difference between attitude scores on gender either. However, as teachers and pre-service teachers kept up with innovations and as their levels of information on and curiosity towards science-and-technology-related news increased, they had higher levels of attitudes towards understanding the objectives of science experiments.
\end{abstract}

Key Words: Science and Technology Lesson, Science Experiments, Pre-Service Science and Technology Teachers, Science Teachers, Attitude.

\footnotetext{
${ }^{*}$ Bu çalışma 5. Uluslararası Eğitim Araştırmaları Birliği Kongresi'nde sözlü bildiri olarak sunulmuştur.
} 


\section{GiRiş}

Günümüz bilim ve teknolojisinin her alanda giderek ilerlemesi sonucunda bilgi birikiminde hızı artış olduğu gözlenmektedir. Bireylerin bu gelişleri takip ederek kendi yaşamlarına entegre etmeleri önemli bir unsurdur. Bu durum özellikle fen eğitiminde büyük bir role sahiptir (Tan ve Temiz, 2003). Bilim ve teknolojideki hı, bilginin üretilmesinde, bilginin kullanılmasında ve bilgiyi üretenlerin yetiştirilmesinde ne kadar önemli olduğunu göstermektedir(Bozdoğan ve Yalçın, 2004).

19. yüzyıldan itibaren laboratuvar yöntemi fen bilimlerinin temel faktörlerinden biri olarak kabul edilerek önemi giderek artış göstermiştir. Bu nedenle de ülkeler öğretim programlarında laboratuvar yöntemlerine yer vererek bireylerin muhakeme, eleştirel düşünme becerisi, bilgiyi anlama ve yorumlama, bilgi üretme becerileri kazanmalarını hedeflemektedir. Günümüzde laboratuvar bir konuda ispat yapma yerinden çok buluş ve bilgi edinme yollarını öğrenme merkezidir (Ayas, Karamustafaoğlu, Sevim ve Karamustafaoğlu, 2002; Kaptan ve Korkmaz, 2001; Jenkins, 2007).

Fen eğitimi ile düşünce sanatının öğretilmesi, deneyimlere dayanan net kavramların zihinde yapılandırılması, olgular arasında neden sonu ilişkisi kurmak, bireylere analiz edebilecekleri yöntemleri öğretmek hedeflenmektedir. Fen eğitimi pozitivist bakış açısından uzaklaşarak daha yenilikçi, bireylerin karşılıklı etkileşim içerisinde sosyal öğrenme ortamlarının oluşturulduğu, etkinliklere dayalı bir süreç haline gelmiştir (Kind, Kind, Hofstein \& Wilson, 2011; Roth, 1999). Ülkemizde de bu durum yenilenen öğretim programları ile geleneksel eğitim anlayışından uzaklaşılarak daha modern, değerleri göz önünde bulunduran, yapılandırmacı, bireyleri araştırma/sorgulamaya yönelten eğitim anlayışı ile sürdürülmektedir.

Fen eğitiminde kullanılabilecek yöntemler arasında laboratuvar kullanımı ve deneyler önemli bir role sahiptir. Bu süreçte öğretilmesi hedeflenen içerik bireylerin kendilerinin yapmaları istenerek ya da gösteri deneyleri yapılarak öğretilmektedir (Özdem, Ertepınar,

Çakıroğlu ve Erduran, 2011; Boaventura, Faria, Chagas \& Galvao, 2013; Uluçınar, Cansaran ve Karaca, 2004; Jenkins, 2007). Laboratuvar kullanımı ile bireylerin kendilerine rahat hissedebilecekleri ortamlarda bilimsel düşünme yeteneği, bir bilim insanın nasıl çalıştığını anlama, çıkarım yapma, araştırma yapma, bilgiyi kullanma ve gözlem yapma gibi becerileri artmaktadır (Kind, Kind, Hofstein \& Wilson, 2011; Uluçınar, Cansaran ve Karaca, 2004; Yenice Balım ve Aydın, 2008; Jenkins, 2007). Öğretmen merkezli gerçekleştirilen fen deneyleri ise öğrencilerin bilgiyi yapılandıramayan, öğrencileri tartışmaya yöneltmeyen, öğrencilerde 
eleştirel becerileri gelişmeyen bireyler olmalarına zemin hazırlar. Öğretmenlerin süreçte bir rehber/yol gösterici olarak görev alması bireylerin gelişiminde önemli role sahiptir. Öğretmen yetiştirme kurumlarının yenilenen öğretim programlarında öğretmenlerin görevlerinden biri de süreç boyunca öğrencilerin bilgiye ulaşmalarını ve kendi zihinlerinde yapılandırmalarına yardımcı olan unsur olarak belirtilmiştir. Fen ve teknoloji öğretmen adaylarının lisans eğitimleri boyunca aldıkları fen deneyleri/etkinliklerine yönelik dersler ile bilimsel süreç becerilerinde, belirlenen bir konuya eleştirel ve günlük yaşam ile ilişkilendirme becerilerinde artış gözlenebilir. Fakat yapılan araştırmalar öğretmen ve öğretmen adaylarının fen deneyleri konusunda yetersiz olduklarını göstermektedir (Boaventura, Faria, Chagas ve Galvao, 2013; Özdem, Ertepınar, Çakıroğlu ve Erduran, 2011).

Fen derslerinde yapılan deneylerin somut deliller ile bireylerin problem çözme becerilerini geliştirmesi, belirli bir olaya yönelik eleştirel düşünme becerisi, bilimsel tartışma becerisi, araştırma/sorgulama ve alanyazında bahsedilen hands-on, minds-on etkinliklerini geliştirmesi beklenmektedir (Özdem, Ertepınar, Çakıroğlu ve Erduran, 2011). Fen laboratuvarları öğretilmesi hedeflenen bir konunun öğrencilere ilk elden deneyimi veya gösteri yöntemi ile sunulduğu ortamlardır. Laboratuvar ortamında öğretimin doğası, olayların deneme yanılma sonucu, ispatlanarak bilgiye ulaşılmasıdır.

Fen deneylerinin istenilen amaçlara ulaşmasında temel unsur fen ve teknoloji öğretmenleridir (Yıldız, Akpınar, Aydoğdu ve Ergin, 2006). Fen eğitimcileri tasarladıkları fen deneyleri ile bireylerin sürece bilişsel ve duyuşsal alan ile katılmalarını, bilimsel kavramları anlamalarını, ilgi ve motivasyonlarının artmasını, pratik ve araştırma becerilerinin artmasını hedeflemektedirler (Lee, Lai, Yu \& Lin, 2012; Boaventura, Faria, Chagas \& Galvao, 2013; Jenkins, 2007; Prades \& Espinar, 2010). Ayrıca Lee, Lai, Yu \& Lin (2012) fen deneyleri ve laboratuvar etkinliklerine katılan öğrencilerin daha başarılı olduklarını vurgulamaktadır. Fen deneylerinin amacı bireylerin kuramsal ve teorik bilgiyi kavramalarını, bilimsel yöntemlerin doğasını, bilimsel araştırmayı anlamaları ve kullanmalarını, öğrenilen bilgilerin uygulama aşamasında neler yapılması gerektiğini kavramalarını, eleştirel ve analitik düşünme becerilerinin artmasını, fen bilimlerine olan ilgilerinin artmasını sağlamaktır (Ottander \& Grelsson, 2006).

Fen laboratuvarları ile sağlanan öğrenci merkezli eğitim, öğrenme ortamına gelen öğrencilerin ön bilgi ve kavram yanılgılarını tespit etmede, bilgilerin bilimsel bir şekilde yapılanmalarını, bireylerin yaparak-yaşayarak deneyim kazanma ve tartışma olanakları 
sağlamaktadır (Uluçınar, Doğan ve Kaya, 2008; Boaventura, Faria, Chagas \& Galvao, 2013). Laboratuvar ortamları öğrencilerin araştırma yapma, problem becerisi kazanma, el ve iletişim beceriler kazanmalarına olanak sağlayarak daha kalıcı, anlamlı öğrenmelerin gerçekleşmelerini sağlar. Ayrıca laboratuvar uygulamaları ile bireylerin fen ve fen derslerine yönelik olumlu tutum geliştirmelerinde etkili bir araçtır (Uluçınar, Doğan ve Kaya, 2008).

Tutum Magno (2003)'e göre belirli bir objeye karşı olumlu ya da olumsuz öğrenilmiş tutarlı davranışlar olarak tanımlanmaktadır. Tutum bilgi, beceri ve davranış olarak üç unsurdan oluşur. Tutumların davranış değil, davranış gösterme eğilimidirler. Tutum tanımlanması zor olan duyuşsal bir değişken olmakla birlikte 'fenne yönelik tutum' ise bilim ürünü olan bir nesneye, fen dersine veya bilimin toplum üzerindeki yansımaları inanç sistemi, değerler bütünü olarak da tanımlanabilir. Fen'e yönelik tutumlar, fen dersinde öğrenci katılımına ve etkili performans göstermeyle ilgilidir (Norby, 2003). Öğrenme-öğretme sürecinde öğretmenlerin tutum ve davranışları öğrencilerin tutumları üzerinde etkilidir. Öğrenciler yeni bir sınıfta öğretmenleri ile tanıştıklarında, öğretmenden gelecek herhangi bir etkileşime açıktır. Süreç boyunca öğrenciler öğretmeni tanırlar, öğretmene yönelik duygu ve düşüncelerini geliştirirler. Öğretmen-öğrenci ilişkisinde öğretmenlerin egemen- boyun eğen ya da düşmanca- şefkatli tutumları öğrencilerin derse olan tutumlarını etkilemektedir (den Brok, Fisher \& Koul 2005).

\subsection{Illgili Çalışmalar}

İlgili alanyazın incelendiğinde öğrencilerin fen dersi etkinlikleri ve deneylerine yönelik görüşlerini araştıran çalışmalar yapıldığı görülmektedir (Boaventura, Faria, Chagas \& Galvao, 2013). Bacey \& Francis (2011) yapmış oldukları deneysel çalışmalarında üniversite öğrencilerinin ( $n=1000)$ araştırma sorgulamaya dayalı öğretim ve probleme dayalı öğretim ile gerçekleşen fen deneylerinin öğrencilerin tutumlarına yönelik etkisini heyecan, zorluk, zaman kısıtlaması, materyal gibi değişkenler açısından incelemişlerdir. Çalışma sonunda öğrencilerin deneylerin her bir basamağını takip edebildiklerini ve fen öğreniminde ilgili konularda alan gezilerinin önemli olduğu sonucuna varmışlardır. Prades \& Espinar (2010) yapmış oldukları görüşmeler ile öğretmen adaylarının fen laboratuvarlarında yapılan kimya deneylerini teorik ve uygulama aşamaları, neler yapılması gerektiği açısından değerlendirmelerini istemişlerdir. Araştırmacılar kimya eğitiminde laboratuvar kullanımının teoriden uygulamaya geçiş ve öğrencilere bilimsel süreç becerileri kazandırma önemli olduğu sonucuna varılmıştır. Hong, Lin \& Lawrenz (2008) karma yöntem araştırması (tek grup ön-son test deneysel desen ve görüşme) kullandıkları çalışmalarında geliştirmiş oldukları fenne yönelik tutum ölçeği ile evli ve boşanmış 
olan ailelerin çocuklarının ( $n=106$ 8. Sınıf öğrencisi) fen deneyleri ve fen dersine yönelik tutumlarını cinsiyet, öğrenme ortamı ve ön-son deneysel performansları, sınıf seviyesi ve akademik başarı değişkenlere göre incelemişlerdir. Araştırmacılar çalışma sonunda fen deneyleri ve uygulamalarının öğrencilerin fen dersine yönelik tutumlarını olumlu yönde geliştirdiğini vurgulamışlardır. Wang \& Berlin (2010) nicel tarama çalışmalarında Tayvan'daki ortaokul öğrencilerinin ( $n=265$ ) fen sınıflarına yönelik dersleri ile fen deneyleri, derse katılım ve güvenlerini cinsiyet ve sınıf seviyesine göre geliştirmiş oldukları ölçek ile incelemişlerdir. Araştırmacılar yapmış oldukları analizler sonucunda cinsiyet ve sınıf seviyesi değişkenlerinin öğrencilerin fenne yönelik tutumlarında etkisi olmadığını belirtmişlerdir. Danielsson \& Linder (2010) İsveç'te bir üniversitede öğrenim görmekte olan 13 üniversite öğrencisi ile yapmış oldukları yarı yapılandırımış görüşmelerde cinsiyet teorisi çerçevesinde fizik derslerinde yapmış oldukları fen deneylerini önceki bilgilerini, neler öğrendiklerini, bir öğrenci olarak nasıl düşündüklerini ön planda tutarak içerik bilgisi ve fiziğin kendisi ile ilişkilendirmelerini hedeflemişlerdir. Çalışma sonunda elde edilen verilere göre cinsiyet merkezli fizik öğrenmede kız öğrencilerin daha başarıları oldukları sonucuna varılmıştır.

Ülkemizde yapılan çalışmalar incelendiğinde Yıldız ve diğerleri (2006) nicel tarama çalışmalarında fen ve teknoloji öğretmenlerinin ( $n=87)$ fen deneylerinin amaçlarına yönelik tutumlarını cinsiyet, mesleki kıdem, mezun olunan alan, eğitim düzeyi, okulda fen laboratuvarının bulunma durumu, fen laboratuvarındaki donanımın yeterli olup olmaması, okuldaki fen laboratuvarını kullanma sıklığı değişkenleri ile geliştirmiş oldukları ölçek ile incelemişlerdir. Araştırmacılar çalışma sonunda yapılan analizler doğrultusunda öğretmenlerin tutumlarında mesleki kıdemleri, okulda fen laboratuvarının bulunma durumu ve fen laboratuvarındaki donanımın yeterli olup olmaması değişkenlerinde anlamlı farklılaşmanın olduğunu belirtmişlerdir. Kocakülah ve Savaş (2011) yapmış oldukları durum çalışmalarında 3. sınıf fen bilgisi öğretmen adaylarının $(n=61)$ deney tasarlama ve uygulamaya yönelik görüşleri ve bilgi düzeylerini araştırmışlardır. Çalışma sonunda elde edilen bulgular doğrultusunda öğrencilerin dersin işlenişine ilişkin görüşlerinin olumlu olduğu, öğrencilerin deney tasarlama ve uygulama aşamalarında çeşitli sıkıntılarla karşılaştıkları (malzeme eksikliği, gerekli içerik ve uygulama bilgisi eksikliği vb) ve öğretmen adaylarının bazı teorik bilgi eksiklikleri ya da özgüven eksiklikleri olduğu ancak laboratuvar çalışmalarının bu eksiklikleri giderdiği sonuçlarına ulaşmışlardır. 


\section{2. Çalışmanın Amacı}

$\mathrm{Bu}$ çalışmanın amacı fen ve teknoloji öğretmen ve öğretmen adaylarının fen deneylerinin amaçlarını kavramaya yönelik tutumlarının bazı değişkenlere göre incelemektir. Fen deneylerinin etkililiğini araştırmaya yönelik yapılan çalışmaların genellikle öğretmen adayları ile gerçekleştirilmiş olduğu görülmektedir. Çalışmadan elde edilen sonuçlar ile fen ve teknoloji öğretmen adayları ile öğretmenlerinin fen deneylerine yönelik tutumları karşılaştırılarak mevcut durum ortaya koymak hedeflenmektedir. Çalışmadan elde edilen sonuçlar aynı zamanda fen deneylerine yönelik etkileyen faktörler ile ilgili bilgiler sunacaktır.

\section{YÖNTEM}

\subsection{Araştırma Modeli}

Bu araştırmada nicel tarama modeli kullanılmıştır. Tarama modeli Karasar (2010) tarafından geçmişte ya da halen var olan bir durumu ortaya çıkarmayı amaçlayan bir çalışma olarak tanımlanırken; Büyüköztürk, Çakmak, Akgün, Karadeniz ve Demirel (2009) tarafından ise bir durum ya da olaya ilişkin katılımcıların görüşlerinin veya ilgi, yetenek, tutum vb. özelliklerinin belirlendiği çalışmalar olarak tanımlanmaktadır.

\subsection{Evren ve Örneklem}

Çalışmanın evrenini Türkiye'nin 7 farklı coğrafi bölgesinde görev yapan fen ve teknoloji öğretmenleri ve Çanakkale Onsekiz Mart Üniversitesi Eğitim Fakültesi İlköğretim bölümü Fen Bilgisi Eğitimi Anabilim Dalında öğrenim gören son sınıf öğretmen adayları oluşturmaktadır. Çalışmanın örneklemi ise 57 fen ve teknoloji öğretmeni ve 71 fen ve teknoloji öğretmen adayından oluşmaktadır. Örneklem belirlenirken seçkisiz olmayan örnekleme yöntemlerinden uygun örnekleme yöntemi kullanılmıştır. Uygun örnekleme yöntemi zaman, para ve işgücü açısından var olan sınırlılıklar nedeniyle örneklemin kolay ulaşılabilir ve uygulama yapılabilir birimlerden seçilmesidir (Büyüköztürk ve diğerleri, 2009).

\subsection{Veri Toplama Aracı}

Araştırmada veri toplama aracı olarak Yıldız ve diğerleri (2006) tarafından geliştirilen 40 maddelik Cronbach $a=0.96$ olan, tek boyutlu "Fen Deneylerinin Amaçlarına Yönelik Tutum Ölçeği" (FDAYTÖ) kullanılmıştır. FDAYTÖ, likert tipi beşli dereceleme sistemine göre geliştirilmiş ve her tutum ifadesi için "tamamen katılıyorum" (5 puan), "katılıyorum" (4 puan), "kararsızım" (3 puan), "katılmıyorum" (2 puan) ve "kesinlikle katılmıyorum" (1 puan) şeklinde puanlanarak kullanılmıştır. Ölçeğin puanlarının dağıımında alınabilecek en düşük puan 40, en yüksek puan 
ise 200 'dür. Yapılan araştırmada elde edilen verilere göre Cronbach alfa güvenirlik katsayısı 0.89 olarak hesaplanmıştır.

\subsection{Veri Analizi}

Araştırmada kullanılan ölçeklerden elde edilen veriler bilgisayarda SPSS 21.0 ístatistik Programı kullanılarak çözümlenmiştir. Verilerin çözümlenmesi amacıyla Aritmetik Ortalama, Standart Sapma, ilişkisiz örneklemler t testi, Tek Yönlü Varyans Analizi kullanılmış, her birinin kullanıldığı yerler ilgili bulgular ele alınırken açıklanmıştır. Verilerin normal dağııı gösterip göstermediğini anlamak için One-Sample Kolmogorov-Smirnov testi yapılmıştır. Test sonucunda $p$ değeri ise .85 olarak bulunmuştur. $p$ değerinin .05 den büyük çıkması, bu anlamlılık düzeyinde verilerin normal dağılımdan anlamlı sapma göstermediği şeklinde yorumlanır (Büyüköztürk, 2011).

\section{BULGULAR VE YORUM}

Bu bölümde araştırma sorularına cevap verecek şekilde her bir araştırma sorusu için yapılan analizler sırasıyla tablolar halinde sunulmuştur.

\section{Fen ve Teknoloji Öğretmen ve Öğretmen Adaylarının Fen Deneylerinin Amaçlarını Kavramaya Yönelik Tutumlarına İlişkin Bulgular}

Fen ve teknoloji öğretmen ve öğretmen adaylarının fen deneylerinin amaçlarını kavramaya yönelik tutumlarından elde edilen bulgular tablo 1 de sunulmuştur.

Tablo 1: Fen ve Teknoloji Öğretmen ve Öğretmen Adaylarının Fen Deneylerinin Amaçlarını Kavramaya Yönelik Tutum Ölçeğinden Aldıkları Puanlara İlişkin t-testi Sonuçları

\begin{tabular}{|c|c|c|c|c|c|c|c|}
\hline & & $\mathbf{N}$ & $\mathrm{X}$ & SD & $d f$ & $t$ & $p$ \\
\hline \multirow{2}{*}{ Grup } & Öğretmen & 57 & 181.80 & 14.48 & \multirow{2}{*}{126} & \multirow{2}{*}{.39} & \multirow{2}{*}{.69} \\
\hline & Öğretmen A. & 71 & 182.91 & 16.46 & & & \\
\hline
\end{tabular}

p>.05 (Öğretmen A: Öğretmen Adayı)

Tablo 1'e göre; fen ve teknoloji öğretmen ve öğretmen adaylarına göre fen deneylerinin amaçlarını kavramaya yönelik tutumlarının anlamlı olarak değişmediği görülmektedir $(t(126)=.39, p>.05)$. Bu bulguya göre, öğretmen ve öğretmen adaylarının fen deneylerinin amaçlarını kavramaya yönelik tutumlarının benzer olduğu söylenebilir. 
Cinsiyet Değişkenine Göre Fen ve Teknoloji Öğretmen ve Öğretmen Adaylarının Fen Deneylerinin Amaçlarını Kavramaya Yönelik Tutumlarına İlişkin Bulgular

Fen ve teknoloji öğretmen ve öğretmen adaylarının fen deneylerinin amaçlarını kavramaya yönelik tutum ölçeğinden aldıkları puanların cinsiyete göre t-testi sonuçları Tablo 2'de sunulmuştur.

Tablo 2: Fen ve Teknoloji Öğretmen ve Öğretmen Adaylarının Fen Deneylerinin Amaçlarıı Kavramaya Yönelik Tutum Ölçeğinden Aldıkları Puanların Cinsiyete Göre t-testi Sonuçları

\begin{tabular}{lccccccc}
\hline & Cinsiyet & $\mathbf{N}$ & $\mathbf{X}$ & SD & $\boldsymbol{d f}$ & $\boldsymbol{t}$ & $\boldsymbol{p}$ \\
\hline \multirow{2}{*}{ FDAYTÖ } & Bayan & 34 & 182.93 & 15.50 & \multirow{2}{*}{126} & \multirow{2}{*}{62} & .53 \\
\cline { 2 - 5 } & Erkek & 71 & 181.00 & 15.88 & & & \\
\hline
\end{tabular}

$p>.05$

Tablo 2'ye göre; cinsiyetlerine göre fen ve teknoloji öğretmen ve öğretmen adaylarının fen deneylerinin amaçlarını kavramaya yönelik tutumlarının anlamlı olarak değişmediği görülmektedir $(\mathrm{t}(126)=.62, \mathrm{p}>.05)$. Bu bulguya göre, cinsiyete göre öğretmen ve öğretmen adaylarının fen deneylerinin amaçlarını kavramaya yönelik tutumlarının benzer olduğu söylenebilir.

Fen ve Teknolojideki Yenilikleri Takip Etme Durumuna Göre Öğretmen ve Öğretmen Adaylarının Fen Deneylerinin Amaçlarını Kavramaya Yönelik Tutumlarına illişkin Bulgular

Fen ve teknolojideki yenilikleri takip etme durumuna göre öğretmen ve öğretmen adaylarının fen deneylerinin amaçlarını kavramaya yönelik tutumlarına ilişkin bulgular Tablo 3'te sunulmuştur.

Tablo 3: Fen ve Teknoloji Öğretmen ve Öğretmen Adaylarının Fen Deneylerinin Amaçlarını Kavramaya Yönelik Tutum Ölçeğinden Aldıkları Puanların Fen ve Teknolojideki Yenilikleri Takip Etme Durumuna Göre t-testi Sonuçları

\begin{tabular}{cccccccc}
\hline & $\begin{array}{c}\text { Takip } \\
\text { Durumu }\end{array}$ & $\mathbf{N}$ & $\mathbf{X}$ & SD & $\boldsymbol{d f}$ & $\boldsymbol{t}$ & $\boldsymbol{p}$ \\
\cline { 1 - 7 } FDAYTÖ & Evet & 67 & 185.32 & 14.40 & \multirow{2}{*}{126} & 2.24 & $.026^{*}$ \\
\cline { 2 - 6 } & KIsmen & 61 & 179.22 & 16.27 & & & \\
\hline
\end{tabular}

$* p<.05$ 
Tablo 3'e göre; fen ve teknolojideki yenilikleri takip etme durumuna göre fen ve teknoloji öğretmen ve öğretmen adaylarının fen deneylerinin amaçlarını kavramaya yönelik tutumlarının anlamlı olarak değiştiği görülmektedir $(t(126)=2.24, p<.05)$. Bu bulguya göre, fen ve teknolojideki yenilikleri takip edenler ( $X=185.32)$, kısmen takip edenlere $(X=179.22)$ göre fen deneylerinin amaçlarını kavramaya yönelik tutumlarının daha yüksek olduğu söylenebilir.

Fen ve Teknoloji İle İlgili Haber ve Bilgileri Merak Düzeyine Göre Öğretmen ve Öğretmen Adaylarının Fen Deneylerinin Amaçlarını Kavramaya Yönelik Tutumlarına illişkin Bulgular

Fen ve teknoloji ile ilgili haber ve bilgileri merak düzeyine göre öğretmen ve öğretmen adaylarının fen deneylerinin amaçlarını kavramaya yönelik tutumlarına ilişkin bulgular Tablo 4'te sunulmuştur.

Tablo 4: Fen ve Teknoloji Öğretmen ve Öğretmen Adaylarının Fen Deneylerinin Amaçlarını Kavramaya Yönelik Tutum Ölçeğinden Aldıkları Puanların Fen ve Teknoloji ile ilgili Haber ve Bilgileri Merak Düzeyine Göre ANOVA Sonuçları

\begin{tabular}{|c|c|c|c|c|c|c|c|}
\hline & Merak & & & & & & Anlamlı Fark \\
\hline & düzeyi & $\mathbf{N}$ & $x$ & SD & $\mathbf{F}$ & p & \\
\hline \multirow{4}{*}{ : } & Çok az & 12 & 171.50 & 16.08 & \multirow{4}{*}{3.38} & \multirow{4}{*}{$.037^{*}$} & \multirow{4}{*}{$\begin{array}{l}\text { Orta-çok az } \\
\text { Çok-Çok az }\end{array}$} \\
\hline & Orta düzey & 91 & 183.56 & 15.29 & & & \\
\hline & Çok & 25 & 183.52 & 14.85 & & & \\
\hline & Toplam & 128 & 182.42 & 15.56 & & & \\
\hline
\end{tabular}

$* p<.05$

Tablo 4'e göre; fen ve teknoloji ile ilgili haber ve merak düzeyine göre fen ve teknoloji öğretmen ve öğretmen adaylarının fen deneylerinin amaçlarını kavramaya yönelik tutumlarının anlamlı olarak değiştiği görülmektedir $(t(126)=3.38, p<.05)$. Bu bulguya göre, öğretmen ve öğretmen adaylarının fen ve teknoloji ile ilgili haber ve bilgileri merak düzeyleri arttıkça fen deneylerinin amaçlarını kavramaya yönelik tutumlarının arttığı söylenebilir.

\section{SONUÇ, TARTIŞMA VE ÖNERILER}

Yapılan çalışmada fen ve teknoloji öğretmenleri ile fen ve teknoloji öğretmen adaylarının fen deneylerinin amaçlarını kavramaya yönelik tutumları araştııılmıştır. Elde edilen bulgulara göre fen deneylerinin amaçlarını kavramaya yönelik tutumlar öğretmen ve öğretmen adayına göre anlamlı olarak değişmemektedir. 
Fen ve teknoloji öğretmen ve öğretmen adaylarının fen deneylerinin amaçlarını kavramaya yönelik tutumları cinsiyet değişkeni açısından incelendiğinde anlamlı bir fark olmadığı gözlenmiştir. Yıldız ve diğerleri (2006) yapmış oldukları çalışmalarında fen ve teknoloji öğretmenlerinin fen deneylerine yönelik tutumları ile cinsiyet değişkeni araştırmış ve tutumların cinsiyet değişkenine göre değişmediği sonucuna varmışlardır. Bu bulgunun nedeni eğitim-öğretimde fırsat ve imkanların eşit şekilde sunulması yorumlanabilir. Benzer şekilde Wang \& Berlin (2010) çalışmalarında Tayvan'da ilköğretim öğrencileri ile gerçekleştirdiği çalışmasında öğrencilerin fen deneyleri ve etkinliklerine yönelik tutumları ile cinsiyet değişkeni arasında anlamlı bir fark olmadığını vurgulamıştır. Fakat Hong, Lin \& Lawrenz (2008) çalışmalarında boşanmış ailelerin çocuklarının fen deneyleri ve etkinliklerine yönelik tutumları ile cinsiyet değişkeni arasında anlamlı bir farklılık olduğunu belirtmişlerdir.

Fen ve teknolojideki yenilikleri takip eden öğretmen ve öğretmen adaylarının fen deneylerinin amaçlarını kavramaya yönelik tutumları kısmen takip eden öğretmen ve öğretmen adaylarından daha yüksektir. Fakat Kocakülah ve Savaş (2006) çalışmalarında fen ve teknoloji öğretmenlerinin fen deneylerini uygulama süreçlerinde bazı konularda teorik bilgi eksikliğinden dolayı sorunlar yaşadıklarını belirtmişlerdir. Kavcar (2002) nitelikli öğretmen yetiştirmede öğretmen yetiştirme kurumlarında verilen eğitimin kalitesinin arttırılması gerektiğini ve laboratuvar uygulamalarının öğrencilerin öğretmenlik hayatlarında mesleki deneyim açısından önemli bir yere sahip olduğunu vurgulamaktadır.

Fen ve teknoloji öğretmen ve öğretmen adaylarının fen ve teknoloji ile ilgili haber ve bilgileri merak düzeyi arttıkça fen deneylerinin amaçlarını kavramaya yönelik tutumları da artmaktadır. Fen ve teknoloji öğretmenleri ile fen ve teknoloji öğretmen adaylarının fen ve teknoloji ile ilgili haber ve bilgileri takip ederek deneylere yönelik bilgi seviyesi ve deney tasarlama becerilerinin gelişebileceği söylenebilir. Kocakülah ve Savaş (2006) çalışmalarında fen ve teknoloji öğretmen adaylarının deney tasarlamaya istekli olduğunu belirtmişlerdir.

Çalışmadan elde edilen bulgular doğrultusunda aşağıda belirtilen öneriler sunulabilir:

- Öğretmen yetiştirme sürecinde güncel fen deneylerine ve uygulamalarına daha fazla yer verilebilir.

- Fen ve teknoloji öğretmen adaylarına lisans eğitimleri boyunca fen ve teknoloji ile ilgili haber ve bilgileri daha fazla takip edebilecekleri uygulamalar sunulmalı, araştırma ödevleri verilebilir. 
- $\quad$ Fen ve teknolojideki yeniliklerin daha kolay takip edileceği TÜBiTAK projeleri daha fazla desteklenmeli, Fen ve Teknoloji öğretmen adaylarının bu projelere katıımı teşvik edilmelidir.

- Fen ve teknoloji ile ilgili yenilikler, yeni bilgi ve haberlerin olduğu web siteleri kurulmalı ve bu siteleri sürekli güncellenmelidir.

\section{KAYNAKLAR}

Ayas, A. P., Karamustafaoğlu, S., Sevim, S. ve Karamustafaoğlu, O. (2002). Genel kimya laboratuvar uygulamalarının öğrenci ve öğretim elemanı gözüyle değerlendirilmesi. Hacettepe Üniversitesi Eğitim Fakültesi Dergisi, 23, 50-56.

Basey, J. M. \& Francis, C. D. (2011). Design of inquiry-oriented science labs: Impacts on students' attitudes. Research in Science \& Technological Education, 29(3), 241-255.

Boaventura, D., Faria, C., Chagas, I. \& Galvão, C. (2013). Promoting science outdoor activities for elementary school children: contributions from a research laboratory. International Journal of Science Education, 35(5), 796-814.

Bozdoğan, A. E. ve Yalçın, N. (2004). Illköğretim fen bilgisi derslerindeki deneylerin yapılma sıklığı ve fizik deneylerinde karşılaşılan sorunlar. Gazi Üniversitesi Kırşehir Eğitim Fakültesi Dergisi, 5(1), 59-70.

Büyüköztürk, Ş. (2011). Sosyal Bilimler İçin Veri Analizi El Kitabı İstatistik, Araştırma Deseni SPSS Uygulamaları ve Yorum, Pegem Akademi Yayınları, Ankara.

Büyüköztürk, Ş., Kılıç, E. K., Akgün, Ö. E., Karadeniz, Ş. ve Demirel, F. (2009). Bilimsel Araştırma Yöntemleri (4. Basım). Ankara: Pegem A Yayıncılık.

Danielsson, A. T. \& Linder, C. (2009). Learning in physics by doing laboratory work: towards a new conceptual framework. Gender and Education, 21(2), 129-144.

den Brok, P., Fisher, D. \& Koul, R. (2005). The importance of teacher interpersonal behavior for secondary science students' attitudes in Kashmir. Journal of Classroom Interaction. 40 (2), 5-19. EJ 768 698. Retrieved May 5, 2011, from ERIC databases.

Hong, Z. R., Lin, H. S. \& Lawrenz, F. (2008). Promoting single-parent family children's attitudes toward science and science performance through extracurricular science intervention in Taiwan. International Journal of Science Education, 30(4), 469-493.

Jenkins, E. (2007). What is the school science laboratory for? Journal of Curriculum Studies, 39(6), 723-736

Kaptan, F. ve Korkmaz, H. (2001). İşbirliğine dayalı fen öğretiminin öğretmen adaylarının öz-yeterlik düzeylerine etkisi. IV. Fen Bilimleri Eğitimi Kongresi 2000, Milli Eğitim Basımevi, Ankara.

Karasar, N. (2010). Bilimsel Araştırma Yöntemi (21. Basım). Ankara: Nobel Yayın Dağıtım.

Kavcar C. (2002). Cumhuriyet döneminde dal öğretmeni yetiştirme. Ankara Üniversitesi Eğitim Bilimleri Fakültesi Dergisi, 35, 1-13. 
Kind,P. M., Kind, V., Hofstein, A. \& Wilson, J. (2011). Peer argumentation in the school science laboratory-Exploring effects of task features. International Journal of Science Education, 33(18), 2527-2558.

Kocakülah, A. ve Savaş, E. (2011). Fen bilgisi öğretmen adaylarının deney tasarlama ve uygulama sürecine ilişkin görüşleri. Ondokuz Mayıs Üniversitesi Eğitim Fakültesi Dergisi, 30(1), 1-28.

Lee, S. Y. L., Lai , Y. C., Yu, H. T. A. \& \& Lin, Y. T. K. (2012). Impact of biology laboratory courses on students' science performance and views about laboratory courses in general: innovative measurements and analyses. Journal of Biological Education, 46(3), 173179.

Magno, C. (2003). Relationship between attitude towards technical education and academic achievement in mathematics and science of the first and second year high school students Caritas Don Bosco School, SY 200 -2003. ED 505 870. Retrieved May 5, 2011, from ERIC databases.

Norby. R. F. (2003). It is a gender issue! Changes in attitudes towards science in a technology based K-8 pre-service preparation science classrooms. the Annual Meeting of the National Association for Research in Science Teaching (Philadelphia, PA, March 23-26, 2003). ED 475 135. Retrieved May 5, 2011, from ERIC databases.

Özdem, Y., Ertepınar, H., Çakıroğlu, J. ve Erduran, S. (2011). The nature of pre-service science teachers' argumentation in inquiry-oriented laboratory context. International Journal of Science Education, 1-28.

Ottander, C. \& Grelsson, G. (2006). Laboratory work: the teachers' perspective. Journal of Biological Education, 40(3), 113-118

Prades, A. \& Espinar, S. R. (2010). Laboratory assessment in chemistry: An analysis of the adequacy of the assessment process. Assessment \& Evaluation in Higher Education, 35(4), 449-461.

Roth, W. M. (1999). Discourse and agency in school science laboratories. Discourse Processes, 28(1), 27-60

Tan, M. ve Temiz, B. K. (2003). Fen öğretiminde bilimsel süreç becerilerinin yeri ve önemi. Pamukkale Üniversitesi Eğitim Fakültesi Dergisi, 1(13).

Uluçınar, Ş., Cansaran, A. ve Karaca, Ö. (2004). Fen bilimleri laboratuvar uygulamalarının değerlendirilmesi. Türk Eğitim Bilimleri Dergisi, 2(4), 465-477.

Uluçınar, Ş., Doğan, A. ve Kaya, O.N. (2008). Sınıf öğretmenlerinin fen öğretimi ve laboratuvar uygulamalarına ilişkin görüşleri. Kastamonu Eğitim Dergisi, 16(2), 485-494.

Wang, T. Z. \& Berlin, D. (2010). Construction and validation of an instrument to measure Taiwanese elementary students' attitudes toward their science class. International Journal of Science Education, 32(18), 2413-2428.

Yenice, N., Balım, A. G. ve Aydın, G. (2008). Biyoloji öğretmenlerinin laboratuvar dersine yönelik tutumları ve teknolojik yenilikleri izleme eğilimleri. Kastamonu Eğitim Dergisi,16(2), 469-484.

Yıldız, E., Akpınar, E., Aydoğdu, B. ve Ergin. Ö. (2006). Fen bilgisi öğretmenlerinin fen deneylerinin amaçlarına yönelik tutumları. Türk Fen Eğitimi Dergisi, 3(2), 2-18. 


\section{SUMMARY}

A rapid increase in knowledge accumulation is observed due to current science and technology developments in every field. It is significant for individuals to follow these developments and integrate them in their lives. This plays an important role particularly in science education. Rapid developments in science and technology refer to the importance of producing and using knowledge and educating those produce knowledge. Laboratory method has been considered a fundamental factor in sciences since 19th century and it's been increasingly important. Therefore, nations include lab methods in their curricula and want individuals to attain reasoning skills, critical thinking skills, and skills to understand, interpret, and produce knowledge. Contemporary lab is not a place for putting forward proofs but a place for learning discovery and acquiring knowledge. In this process, the content to learn is taught by asking individuals to work on their own or by organizing demonstration experiments. Through lab usage, individuals' scientific thinking skills in environments where they can feel comfortable, and their skills to understand how a science person thinks, to deduct, research, use knowledge, and observe multiply. Experiments conducted within science classes are expected, through concrete evidence, to improve individuals' problem solving skills, critical thinking skills towards a phenomenon, scientific discussion skills, research/inquiry, and hands-on, minds-on activities mentioned in the literature. Science labs are where students are presented a subject to be taught via firsthand experience or demonstration method. The nature of teaching in a lab medium is about reaching the knowledge through proof as a result of trial-error process. The basic element in science experiments to achieve desired purposes is the science and technology teacher. Science educators target at individuals' participation in the process through the affective and cognitive domains, understanding scientific concepts, improvement in their interest and motivation, and increasing their practical and research skills via science experiments conducted. As attitude is an affective variable, difficult to define, attitude towards science may be about an object, a product of science, and the science class or it may be defined as the belief system, community's reflections on science, and the whole of values. Attitudes towards science are about students' participation in science class and effective performance. Teachers' attitudes and behaviors are influential on students' attitudes in teaching-learning process. When the students are introduced with a teacher in a new class, they are open to any interaction with the teacher. Throughout the process, students get to know their teachers and develop feelings and opinions about the teachers. Within the teacher-student relationship, teachers' dominant- submissive or hostile-affectionate attitudes influence students' attitudes towards the class. When the relevant literature is reviewed, it is observed that many studies have been conducted to investigate students' views of science class activities and experiments. The purpose of the current study is to investigate science and technology teachers' and pre-service teachers' attitudes towards understanding the aims of science experiments, on some variables. When studies researching the effectiveness of science experiments are reviewed, it is seen that these studies have usually included pre-service teachers. With results of the current study, it is aimed to compare science and technology teachers' and pre-service teachers' attitudes towards science experiments and to reveal the current state. 
Qualitative survey model is used in the current research. Sample of the study consists of 57 science and technology teachers and 71 science and technology pre-service teachers. A single-dimension and 40-item "Attitude towards Purposes of Science Experiments Scale" (APSES), with Cronbach's $\alpha=0.96$, developed by Yildiz et al. (2006) was used as the data collection tool. APSES is a five-item Likert-type scale with "I strongly agree" (5 points), "I agree" (4 points), "I am undecided" (3 points), "I disagree" (2 points), and "I strongly disagree" (1 point) for each attitude expression. The lowest possible score on the scale is 40 whereas the highest possible score is 200. Based on the data obtained in the research, Cronbach's alpha reliability coefficient has been calculated as 0.89 . Data obtained from the scales used within current research were analyzed through SPSS 21.0 Statistical Software. In the analysis, Arithmetical average, Standard Deviation, independent sample $t$ test, and One-way Variance Analysis were used and these were mentioned with the related data.

The current research investigated science and technology teachers' and pre-service teachers' attitudes towards understanding the aims of science experiments, with two-group comparison, on gender variable and catching up with developments in technology. Analyses results showed science and technology teachers' and pre-service teachers' attitudes towards understanding the aims of science experiments. Based on the obtained findings, attitudes towards understanding the aims of science experiments do not significantly differ on teachers and pre-service teachers. When analyzed for gender, it was observed that science and technology teachers' and pre-service teachers' attitudes towards understanding the aims of science experiments do not significantly differ. The reason for that finding may be the equal opportunity and possibilities provided in education. Attitudes towards understanding aims of science experiments by teachers and pre-service teachers who catch up with developments in science and technology are higher than those teachers and preservice teachers who partially catch up with developments in science and technology. As the teachers' and pre-service teachers' curiosity levels towards science and technology news and information increase, their attitudes towards understanding the aims of science experiments improve. It may be said that science and technology teachers' and pre-service teachers' levels of information associated with experiments and skills of designing experiments will improve by catching up with science and technology news and information updates. Based on the findings of the current research, the following are recommended: latest science experiments and applications must be included more in teacher education process; applications by which science and technology pre-service teachers can catch up with science and technology-related news and information must be offered in undergraduate education; research assignments must be provided; TUBITAK (Scientific and Technological Research Council of Turkey) projects through which science and technology innovations can be followed must be supported more; science and technology pre-service teachers must be encouraged to participate in these projects; websites including science and technology innovations, new information, and news must be set up and continuously updated. 